\title{
The effect of comorbidities on the survival of colorectal cancer in the older patients
}

\author{
Ali Kagan Coskun • Aytekin Unlu • Taner Yigit
}

Accepted: 29 September 2014 / Published online: 11 October 2014

(C) Springer-Verlag Berlin Heidelberg 2014

\section{Dear Editor:}

We read the recent article by Hamaker et al. [1] titled "Improved survival for older patients undergoing surgery for colorectal cancer between 2008 and 2011" published online in the International Journal of Colorectal Disease (doi: 10.1007/ s00384-014-1959-y) with great interest [1]. The authors evaluated the impact of an increased application of laparoscopic surgery for colorectal cancer in the Netherlands on overall survival. They concluded that especially for older patients, application of laparoscopy had an advantage for reducing the mortality rate; therefore, the usage of laparoscopy was offered whenever possible by allowing for further improvement of outcomes. When we read the article, we have wondered about a condition. We feel that clarification regarding the following detail would be beneficial.

The physiological, the social, and the psychological conditions of the older people is not the same as the younger people even for the healthy persons [2]. For the older patients undergoing surgery, the risk of facing with the comorbidities is higher than younger patients. This condition diverts the health providers to evaluate the older patients particularly before the operation. Therefore, the estimation of survival with older patients undergoing surgery for colorectal cancer should be done with evaluation of comorbidities such as respiratory and cardiovascular problems [3]. Turrentine et al. have stated that coexisting health conditions as gangrene, ventilator usage, chronic obstructive pulmonary disease, hemiplegia, renal failure hypertension, dyspnea, and preoperative transfusion are the risk factors effecting the survival in older patients for morbidity and mortality [4]. We thought that during the evaluation of the survival for older patients undergoing surgery, these factors should be taken into account for improving the quality of older people's surgical care.

\section{References}

1. Hamaker ME1, Schiphorst AH, Verweij NM, Pronk A (2014) Improved survival for older patients undergoing surgery for colorectal cancer between 2008 and 2011. Int J Colorectal Dis 15. doi: 10.1007/ s00384-014-1959-y

2. Evers BM, Townsend CM Jr, Thompson JC (1994) Organ physiology of aging. Surg Clin N Am 74(1):23-39, Review

3. Charlson ME, Pompei P, Ales KL, MacKenzie CR (1987) A new method of classifying prognostic comorbidity in longitudinal studies: development and validation. J Chron Dis 40(5):373-383

4. Turrentine FE, Wang H, Simpson VB, Jones RS (2006) Surgical risk factors, morbidity, and mortality in elderly patients. J Am Coll Surg 203(6):865-877
A. K. Coskun $(\bowtie) \cdot$ A. Unlu $\cdot$ T. Yigit

Department of Surgery, Gulhane Military Medical Academy,

Ankara, Turkey

e-mail: kagancoskun@gmail.com 